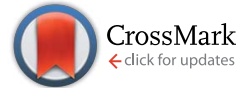

Cite this: Chem. Sci., 2017, 8, 781

\title{
Covalent triazine framework supported non-noble metal nanoparticles with superior activity for catalytic hydrolysis of ammonia borane: from mechanistic study to catalyst design $\dagger$
}

\author{
Zhao Li, ${ }^{\text {ab }}$ Teng He, ${ }^{\text {*a }}$ Lin Liu, ${ }^{a}$ Weidong Chen, ${ }^{\text {ab Miao Zhang, }}{ }^{\text {ab }}$ Guotao Wu ${ }^{a}$ \\ and Ping Chen ${ }^{\text {ac }}$
}

Development of non-noble metal catalysts with similar activity and stability to noble metals is of significant importance in the conversion and utilization of clean energy. The catalytic hydrolysis of ammonia borane (AB) to produce 3 equiv. of $\mathrm{H}_{2}$, as an example of where noble metal catalysts significantly outperform their non-noble peers, serves as an excellent test site for the design and optimization of non-noble metal catalysts. Our kinetic isotopic effect measurements reveal, for the first time, that the kinetic key step of the hydrolysis is the activation of $\mathrm{H}_{2} \mathrm{O}$. Deducibly, a transition metal with an optimal electronic structure that bonds $\mathrm{H}_{2} \mathrm{O}$ and $-\mathrm{OH}$ in intermediate strengths would favor the hydrolysis of $A B$. By employing a covalent triazine framework (CTF), a newly developed porous material capable of donating electrons through the lone pairs on $\mathrm{N}$, the electron densities of nano-sized Co and Ni supported on CTF are markedly increased, as well as their catalytic activities. Specifically, Co/CTF exhibits a total turnover

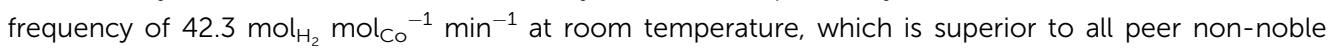
metal catalysts ever reported and even comparable to some noble metal catalysts.

Received 3rd June 2016

Accepted 23rd August 2016

DOI: $10.1039 / \mathrm{c} 6 \mathrm{sc0} 02456 \mathrm{~d}$

www.rsc.org/chemicalscience
Ammonia borane $\left(\mathrm{NH}_{3} \mathrm{BH}_{3}, \mathrm{AB}\right.$ for short), with a hydrogen content of $c a$. $19.6 \mathrm{wt} \%$, is a promising hydrogen storage material attracting tremendous research efforts. ${ }^{8-10}$ Hydrogen can be released from $\mathrm{AB}$ either through pyrolysis or catalytic hydrolysis (eqn (1)). Although the thermal dehydrogenation temperature for $A B$ is mild, there are drawbacks such as stepwise reaction, sample foaming and toxic byproducts. ${ }^{11-13}$ Catalytic hydrolysis of $\mathrm{AB}$, first introduced by $\mathrm{Xu}$, on the other hand, can generate three equivalents of $\mathrm{H}_{2}$ (eqn (1)) rapidly at room temperature. ${ }^{14-16}$ However, the absence of efficient catalysts with low prices made this process still unsuitable for applications.

$$
\mathrm{NH}_{3} \mathrm{BH}_{3}+2 \mathrm{H}_{2} \mathrm{O} \rightarrow \mathrm{NH}_{4}^{+}+\mathrm{BO}_{2}^{-}+3 \mathrm{H}_{2}
$$

Much progress has been made in the development of new structures of catalysts (i.e., amorphous, ${ }^{17}$ nano-particles, ${ }^{18}$ alloyed, ${ }^{19-21}$ core-shelled bimetallic ${ }^{22-24}$ and multimetallic catalysts $^{25}$ ), which usually possess enhanced catalytic performance in comparison to their crystalline or monometallic counterparts in $\mathrm{AB}$ hydrolysis. On the other hand, newly developed functional supports, i.e., metal organic frameworks (MOFs), ${ }^{26-29}$ carbon nanotubes (CNTs), ${ }^{30}$ graphene, ${ }^{31-33}$ carbon nitride, ${ }^{34}$ and organic polymers ${ }^{35,36}$ etc., have exhibited distinct effects on this reaction. For instance, Pt supported on defect-rich CNTs showed superior activity compared to that of pristine and oxygen-doped CNTs due 
to the electronic modification to the metal by the defects. ${ }^{37}$ MOFs, because of their microporous cages, could confine ultrafine $\mathrm{Pt}$ particles, which exhibited extremely high turnover frequency (TOF) for $\mathrm{AB}$ hydrolysis. ${ }^{26}$

Although a number of active catalysts have been reported, the development of non-noble metal catalysts with comparative activity as noble metals is still a scientific challenge for this particular reaction. To design and fabricate an efficient catalyst, it is essential to have a clear understanding of the dehydrogenation mechanism, especially the rate determining step (RDS) in the reaction. Previous mechanistic proposals discussed a concerted dissociation of the $\mathrm{B}-\mathrm{N}$ bond and the hydrolysis of the resulting $\mathrm{BH}_{3}$ intermediate. ${ }^{\mathbf{1 4 , 3 8 - 4 0}}$ The breaking of both $\mathrm{B}-\mathrm{H}$ and $\mathrm{O}-\mathrm{H}$ (the slow step) bonds in the process of hydrolysis of $\mathrm{AB}$, on the other hand, was also proposed. ${ }^{41}$ Recently, a theoretical simulation of the hydrolysis of $\mathrm{AB}$ on a $\mathrm{Ni}_{2} \mathrm{P}$ surface indicated that an energy barrier of $c a .0 .12 \mathrm{eV}$ (of $\mathrm{AB}$ and $\mathrm{H}_{2} \mathrm{O}$ adsorption) was needed to realize the hydrolysis, in which the adsorption and activation of $\mathrm{AB}$ and $\mathrm{H}_{2} \mathrm{O}$ molecules were considered to be the key step for the hydrolysis process. ${ }^{42}$ Although several proposals were put forward, the mechanism observed experimentally is still unclear. Therefore, more experimental work is needed to elucidate the dehydrogenation mechanism, which may further promote the rational design of active catalysts for $\mathrm{AB}$ hydrolysis. Herein, kinetic isotope effect (KIE) measurements were conducted to investigate the RDS of $\mathrm{AB}$ hydrolysis. Our experimental results demonstrate for the first time that the activation of $\mathrm{H}_{2} \mathrm{O}$ is the RDS in $\mathrm{AB}$ hydrolysis. Stimulated by this finding, covalent triazine framework (CTF), a newly developed porous material capable of donating electrons to metals, was selected as a functional support for $\mathrm{Co}$ and $\mathrm{Ni}$ in the present study, aiming to facilitate the activation of water molecules. To our delight, these catalysts did exhibit remarkably improved activities. Specifically, a TOF of $42.3 \mathrm{~mol}_{\mathrm{H}_{2}} \mathrm{~mol}_{\mathrm{Co}}{ }^{-1} \mathrm{~min}^{-1}$ was achieved by the $3 \%$ $\mathrm{Co} / \mathrm{CTF}-1$ catalyst at room temperature, which is the highest value among all non-noble metal catalysts ever reported and even comparable to some noble metal catalysts. ${ }^{43}$

\section{Results and discussion}

\section{KIE measurements}

As mentioned in the introduction section, the RDS for $A B$ hydrolysis needs to be investigated, from which a proper catalyst could be rationally designed. The KIE is considered to be one of the most essential and sensitive tools for the study of the RDS of a reaction. ${ }^{\mathbf{4 4 , 4 5}}$ Specifically, it is calculated by the ratio of rate constants for the reactions involving light $\left(k_{\mathrm{L}}\right)$ and heavy $\left(k_{\mathrm{H}}\right)$ isotopically substituted reactants, i.e., $\mathrm{KIE}=k_{\mathrm{L}} / k_{\mathrm{H}}$, and is classified into primary and secondary kinetic isotope effects. ${ }^{\mathbf{4 6}}$ The primary kinetic isotope effect with a KIE value of 2-7 usually reveals that a bond to the isotopically labelled atom is formed or broken in the RDS. The secondary kinetic isotope effect with a small KIE value of $0.7-1.5$, on the other hand, hints that no bond to the isotopically substituted atom in the reactant is broken or formed in the RDS. To shed light on the RDS of $\mathrm{AB}$ hydrolysis, KIE measurements were carried out using homemade 5\% Co/CNT and 5\% Co/AC catalysts. As shown in Fig. 1a, ca. 3 equiv. of $\mathrm{H}_{2}$ was vigorously generated from $\mathrm{NH}_{3} \mathrm{BH}_{3}$ in $\mathrm{H}_{2} \mathrm{O}$ in 8.3 min catalyzed by $5 \% \mathrm{Co} / \mathrm{CNT}$. Interestingly, $\mathrm{NH}_{3} \mathrm{BD}_{3}$ in $\mathrm{H}_{2} \mathrm{O}$ exhibited similar dehydrogenation behaviour to that of $\mathrm{NH}_{3} \mathrm{BH}_{3}$ in $\mathrm{H}_{2} \mathrm{O}$. To exclude the $\mathrm{H}\left(\mathrm{H}_{2} \mathrm{O}\right)-\mathrm{D}\left(\mathrm{BD}_{3}\right)$ exchange during dissolution and reaction, ${ }^{11} \mathrm{~B}$ nuclear magnetic resonance (NMR) was employed to detect the chemical shift of $\mathrm{B}$ in $\mathrm{NH}_{3} \mathrm{BD}_{3}-\mathrm{H}_{2} \mathrm{O}$ and in $\mathrm{NH}_{3} \mathrm{BH}_{3}-\mathrm{H}_{2} \mathrm{O}$. As shown in Fig. $\mathrm{S} 1, \dagger$ no $\mathrm{H}\left(\mathrm{H}_{2} \mathrm{O}\right)-\mathrm{D}\left(\mathrm{BD}_{3}\right)$ exchange was observed during the test. The experimental results above showed that no kinetic isotopic effect occurred when deuteration occurred at the boron $\left(\mathrm{NH}_{3} \mathrm{BD}_{3}\right)$. However, the hydrolysis of $\mathrm{NH}_{3} \mathrm{BH}_{3}$ in $\mathrm{D}_{2} \mathrm{O}$ showed a slower hydrogen release rate compared to that of $\mathrm{NH}_{3} \mathrm{BH}_{3}$ and $\mathrm{NH}_{3} \mathrm{BD}_{3}$ in $\mathrm{H}_{2} \mathrm{O}$ (Fig. 1). Since $\mathrm{H}-\mathrm{D}$ exchange can easily occur between $\mathrm{D}_{2} \mathrm{O}$ and $\left[-\mathrm{NH}_{3}\right]$ in $\mathrm{AB}$, the resultant $\left[-\mathrm{ND}_{x} \mathrm{H}_{3-x}\right]$ group may also affect the rate of hydrolysis of $\mathrm{AB}$. Actually, since the $\mathrm{NH}_{3}$ group does not participate in the hydrolysis, D substitution on the $\mathrm{NH}_{3}$ side will have little effect on the reaction rate. Similar KIE results were also observed in the $5 \% \mathrm{Co} / \mathrm{AC}$ catalyzed system (Fig. 1b). The KIE values of 2.1 and 2.2 for Co/CNT and $\mathrm{Co} / \mathrm{AC}$ were calculated according to the hydrogen generation rates in $\mathrm{NH}_{3} \mathrm{BH}_{3}-\mathrm{D}_{2} \mathrm{O}$ systems, respectively, which revealed that the activation of $\mathrm{O}-\mathrm{H}$ bonds in $\mathrm{H}_{2} \mathrm{O}$ should be involved in the RDS of $\mathrm{AB}$ hydrolysis, similar to that of $\mathrm{NaBH}_{4}$ hydrolysis. ${ }^{47}$ The involvement of $\mathrm{H}_{2} \mathrm{O}$ activation in the RDS may be partially attributed to its stronger $\mathrm{O}-\mathrm{H}$ bond strength, i.e., the $\mathrm{O}-\mathrm{H}$ bond energy $\left(\sim 493 \mathrm{~kJ} \mathrm{~mol}^{-1}\right)^{48}$ in $\mathrm{H}_{2} \mathrm{O}$ is significantly higher than those of B-N $\left(\sim 117 \mathrm{~kJ} \mathrm{~mol}^{-1}\right)$ and $\mathrm{B}-\mathrm{H}\left(\sim 430 \mathrm{~kJ} \mathrm{~mol}^{-1}\right) .{ }^{49}$ In the homogeneous catalytic dehydrogenation of $\mathrm{AB}$, on the other hand, the activation of both $\mathrm{B}-\mathrm{H}$ and $\mathrm{N}-\mathrm{H}$ bonds is involved in the RDS as evidenced by KIE investigations. ${ }^{50}$

$\mathrm{H}_{2} \mathrm{O}$ molecules can be activated more easily on noble metals (such as $\mathrm{Pt}$ ) than on a non-noble metal surface. ${ }^{51}$ This may explain why Pt or other noble metals perform well in waterbased reactions, such as the hydrogen evolution reaction ${ }^{52}$ and $\mathrm{AB}$ hydrolysis. ${ }^{30} \mathrm{H}_{2} \mathrm{O}$ molecules need to be adsorbed on the metal surface and activated, forming adsorbed $-\mathrm{OH}$ and $-\mathrm{H}$ species. According to the scaling relations, ${ }^{\mathbf{5 3}, 54}$ the adsorption energy of $\mathrm{H}_{2} \mathrm{O}$ on the metal surface should be strong enough to break the $\mathrm{O}-\mathrm{H}$ bond. The adsorption energies of $-\mathrm{OH}$ and $-\mathrm{H}$ on the surface, on the other hand, should be intermediate, which will favor the further conversion of these species and liberation of active sites. Therefore, a suitable catalyst for $\mathrm{AB}$ hydrolysis should have appropriate adsorption energies for $\mathrm{H}_{2} \mathrm{O},-\mathrm{H}$ and
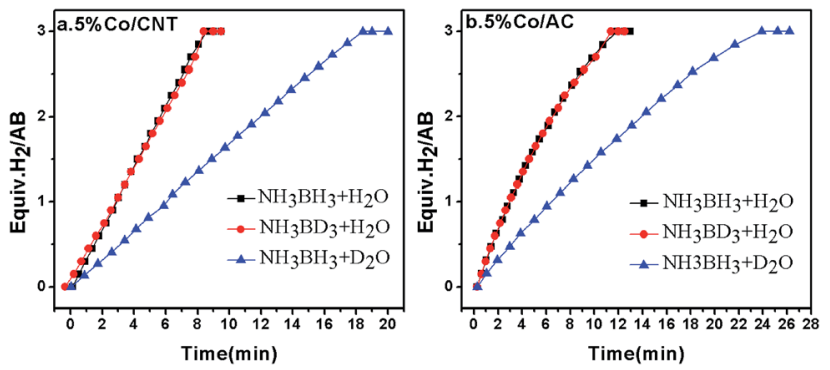

Fig. 1 Hydrogen evolution from $\mathrm{NH}_{3} \mathrm{BH}_{3}$ in $\mathrm{H}_{2} \mathrm{O}$ (black), $\mathrm{NH}_{3} \mathrm{BD}_{3}$ in $\mathrm{H}_{2} \mathrm{O}$ (red), and $\mathrm{NH}_{3} \mathrm{BH}_{3}$ in $\mathrm{D}_{2} \mathrm{O}$ (blue) catalyzed by $5 \%$ Co/CNT (left) and $5 \% \mathrm{Co} / \mathrm{AC}$ (right) at room temperature, $n_{\mathrm{Co}}: n_{\mathrm{AB}}=0.05: 1$. 
-OH species, which will be discussed and fulfilled in the following sections.

\section{Catalyst design and synthesis}

Since the activation of $\mathrm{H}_{2} \mathrm{O}$ is the RDS for hydrolysis of $\mathrm{AB}$, transition metals that can effectively break the $\mathrm{O}-\mathrm{H}$ bond in $\mathrm{H}_{2} \mathrm{O}$ to form $-\mathrm{H}$ and $-\mathrm{OH}$ species of intermediate adsorption strengths are potential catalysts. ${ }^{41}$ In particular, the contribution of support materials to the performance of the final catalysts should be taken into account. The electrochemical hydrogen production from water is usually facilitated by noble metal catalysts which activate water by transferring electrons to the antibonding orbital of a $\mathrm{H}_{2} \mathrm{O}$ molecule. ${ }^{55,56}$ First-principles DFT calculations showed that electron transfer from Nb-doped $\mathrm{SrTiO}_{3}(001)$ to Pt enhanced its capability in the activation of $\mathrm{H}_{2} \mathrm{O}$ molecules. ${ }^{57}$ Experimental results also indicated that moderately negatively charged $\mathrm{Pt}^{\delta-}$, due to the electron donation from the $\mathrm{TiO}_{2}$ nanofiber, performed better with respect to hydrogen evolution from $\mathrm{O}-\mathrm{H}$ splitting in alcohol. ${ }^{58}$ It is worth mentioning that the negatively charged metal catalyst, derived from the electron donation from the support, is in favor of breaking $\mathrm{C}-\mathrm{H}$ and $\mathrm{N}-\mathrm{H}$ bonds as well. For instance, $\mathrm{Ru}$ on an N-containing carbon support exhibited higher hydrogen productivity from ammonia decomposition, which was attributed to electron donation from the support to $\mathrm{Ru} .{ }^{59,60}$ Similarly, Pt species on $\mathrm{N}$-modified $\mathrm{TiO}_{2}$ with high electron density were beneficial to the activation of $\mathrm{C}-\mathrm{H}$ bonds. ${ }^{61}$ Therefore, it is reasonable to deduce that by increasing the electron densities of non-noble metals, such as $\mathrm{Co}$ and $\mathrm{Ni}$, the catalytic performances in $\mathrm{AB}$ hydrolysis could be significantly improved.

A number of investigations disclosed that metal nanoparticles supported on nitrogen modified materials could receive electrons from the support leading to enhanced catalytic performance. ${ }^{62-64}$ Theoretical calculation also disclosed the electron donor states of N-doped CNTs to metal particles. ${ }^{65}$ Besides the electron donation effect, the $\mathrm{N}$-doped supports can also provide anchoring sites for metal particles, leading to a good dispersion of catalyst ${ }^{66,67}$ which facilitates the adsorption of reactant or desorption of products. ${ }^{68}$ However, special treatment is required for the preparation of $\mathrm{N}$-doped carbon materials, for which the $\mathrm{N}$-content and the $\mathrm{N}-\mathrm{C}($ metal) bonding are poorly defined. ${ }^{31,63,69}$ The newly developed covalent triazine frameworks (CTF) by Thomas et al., on the other hand, possess a number of merits including high surface area, well-defined porous structure and high nitrogen content of $c a .17 \%$ and thus can be an ideal support material meeting the requirements mentioned above. ${ }^{\mathbf{7 0 , 7 1}}$ Recent reports discussed the superior performance of CTF over other carbon-based materials as catalyst supports in oxidation reactions $\mathrm{s}^{72-74}$ and hydrogenation/ dehydrogenation reactions. ${ }^{75}$ Herein, we purposely employ CTF-1, a kind of CTF with a microporous structure (pore size of $1.5 \mathrm{~nm}$ ) and a surface area around $700-900 \mathrm{~m}^{2} \mathrm{~g}^{-1}$, as the support to enhance the activity of non-noble metal-based catalysts for hydrolysis of $\mathrm{AB}$.

The as-prepared CTF-1 showed a certain degree of crystallization with two diffraction peaks at around $7.3^{\circ}$ and $26.1^{\circ}$ corresponding to the (100) and (001) planes (Fig. S2 $\dagger$ ). ${ }^{70}$ The 5\% Co/CTF-1 catalyst was synthesized through an impregnation method following the same procedure as for the Co/AC and $\mathrm{Co} / \mathrm{CNT}$ catalysts. After calcination and reduction, the characteristic diffraction peaks of CFT- 1 were maintained in the Co/CTF-1 catalyst. Diffraction peaks belonging to metallic Co or Co compounds cannot be observed in the CTF-1, AC and CNT supported catalysts (Fig. S2 $\dagger$ ), indicating the fine dispersion of nanoparticles on the supports.

Transmission electron microscopy (TEM) images of the three samples showed that all the Co particles are well dispersed in the nanoscale on the supports (Fig. 2), agreeing well with the X-ray diffraction (XRD) measurements. The statistical analysis of the particle size resulted in a mean size of $7.3 \mathrm{~nm}$ with a wide distribution for the Co/CNT catalyst (Fig. 2a and Table S1 $^{\text {) }}$. Although the size of Co particles distributed on AC was hard to calculate due to the ambiguous boundary, an average size of less than $5 \mathrm{~nm}$ was estimated. However, the CTF-1 supported Co has a much smaller mean particle size $(3.3 \mathrm{~nm})$ with a narrow diameter distribution. A high resolution TEM image of Co/CTF1 catalyst in Fig. 2d showed that the interplane spacing of the particle lattice was $0.19 \mathrm{~nm}$, in good agreement with the $\{101\}$ lattice spacing $(0.191 \mathrm{~nm}$ ) of face centered cubic (fcc) Co, which confirmed that metallic Co was formed after $\mathrm{H}_{2}$ reduction. Since CTF-1 is a microporous covalent structure with a pore size of $c a$. $1.5 \mathrm{~nm}$, most of the Co nanoparticles (NPs) on CTF-1 should not be in the pores. Furthermore, considering the hydrophobic property of CTF- $1, \mathrm{Co}^{2+}$ solution may not enter the micropores easily. It is worth mentioning that there are $6 \mathrm{~N}$ atoms at each opening of the CTF-1 pores, which can serve as anchoring sites for the metal NPs as also pointed out in the literature. ${ }^{75-77}$ We deduce that the Co NPs may mainly stay on the edges of the support and/or the openings of the pores, which blocks some channels of CTF-1 consistent with

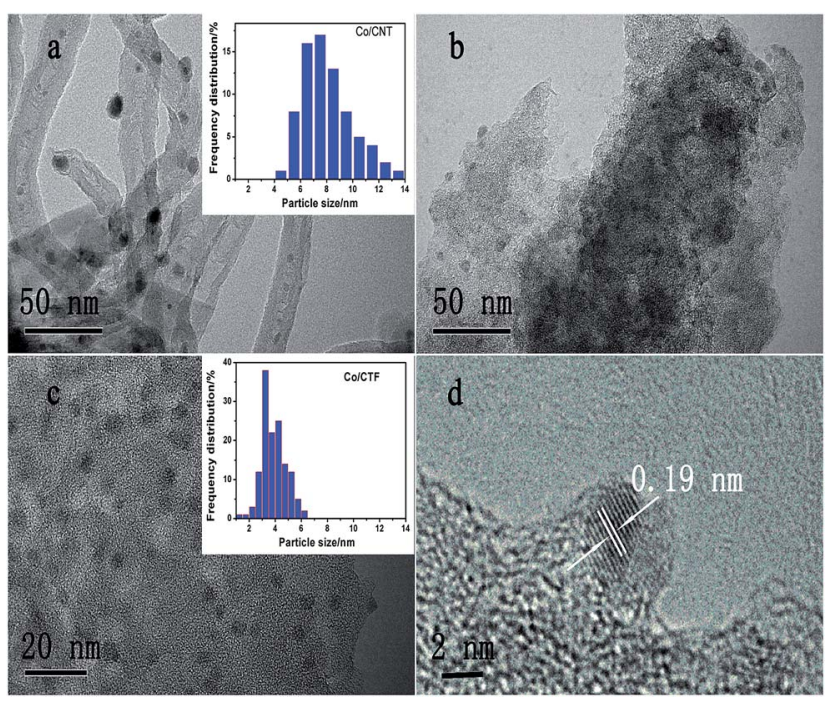

Fig. 2 TEM images and corresponding size histograms of (a) $5 \% \mathrm{Co} /$ CNT, (b) $5 \% \mathrm{Co} / \mathrm{AC}$, (c) $5 \% \mathrm{Co} / \mathrm{CTF}-1$, (d) high resolution image of $\mathrm{Co}$ particles on CTF-1. The average size is calculated from at least 100 nanoparticles. 
a significant decrease of surface area from 947 to $726 \mathrm{~m}^{2} \mathrm{~g}^{-1}$ after Co loading (see Table S1 $\dagger$ ).

\section{Catalytic performance of Co/CTF-1}

To check the promoting effect of CTF-1 to Co, the catalytic properties of $5 \%$ Co/CTF-1 were tested for the hydrolytic dehydrogenation of $\mathrm{AB}$ and compared to those of $\mathrm{Co} / \mathrm{AC}$ and $\mathrm{Co} / \mathrm{CNT}$ as shown in Fig. 3. TOFs were calculated to compare to those in the literature, which were based on the real metal content determined by ICP (Table S1†) following the common methods in the literature. ${ }^{26,31,37}$ As mentioned above, the $5 \% \mathrm{Co} / \mathrm{AC}$ and $5 \% \mathrm{Co} / \mathrm{CNT}$ catalysts exhibited moderate catalytic activities, i.e., ca. 12 and $8.3 \mathrm{~min}$ were needed for each catalyst to complete the dehydrogenation with TOFs of 5.8 and $8.5 \mathrm{~mol}_{\mathrm{H}_{2}} \mathrm{~mol}_{\mathrm{Co}}{ }^{-1} \mathrm{~min}^{-1}$, respectively. As we expected, the $5 \% \mathrm{Co} / \mathrm{CTF}-1$ catalyst showed a remarkably enhanced activity for $\mathrm{AB}$ hydrolysis, i.e., only $\sim 2.0$ min were needed with a total TOF value of $33.5 \mathrm{~mol}_{\mathrm{H}_{2}}$ $\operatorname{mol}_{\mathrm{Co}}{ }^{-1} \mathrm{~min}^{-1}$ which was nearly 6 and 4 times as great as those of $\mathrm{Co} / \mathrm{AC}$ and $\mathrm{Co} / \mathrm{CNT}$, respectively. On further decreasing the $\mathrm{Co}$ loading to $3 \%$, the TOF of Co/CFT-1 can reach as high as $42.3 \mathrm{~mol}_{\mathrm{H}_{2}} \operatorname{mol}_{\mathrm{Co}}{ }^{-1} \mathrm{~min}^{-1}$, that is among the top most active non-noble metal catalysts, if not the highest, ever reported (Table S2 $\dagger$ ) and even comparable to some noble metal catalysts. ${ }^{43}$ In addition, a CTF-1 supported Ni catalyst also showed a significantly enhanced catalytic activity as compared to Ni/AC and Ni/CNT (Fig. 3b), suggesting a general promoting effect of CTF-1. It should be noted that the neat support (CTF-1) had no detectable ability in catalyzing the hydrolytic reaction (Fig. 3).

The kinetics of $\mathrm{AB}$ hydrolysis with different concentrations of catalyst and substrate provide valuable information. Fig. $\mathrm{S} 3 \dagger$ shows the plots of volume of $\mathrm{H}_{2}$ generated versus time for $\mathrm{AB}$ hydrolysis catalyzed by the Co/CTF-1 catalyst with different catalyst and substrate concentrations, where almost linear $\mathrm{H}_{2}$ gas evolution was observed. The hydrogen generation rates versus the concentration of $\mathrm{Co}$ and $\mathrm{AB}$, both in natural logarithmic scale, were plotted in Fig. 4 . The slope of 0.95 of $\ln ($ rate $)$ versus $\ln [\mathrm{Co}]$ indicated that the hydrolysis of $\mathrm{AB}$ catalyzed by the Co/CTF-1 catalyst was first-order with respect to the catalyst concentration, which is consistent with the literature. ${ }^{18}$ However, the slope of 0.06 of $\ln ($ rate) versus $\ln [\mathrm{AB}]$ indicated that the hydrolysis catalyzed by the Co/CTF-1 catalyst was zero-order
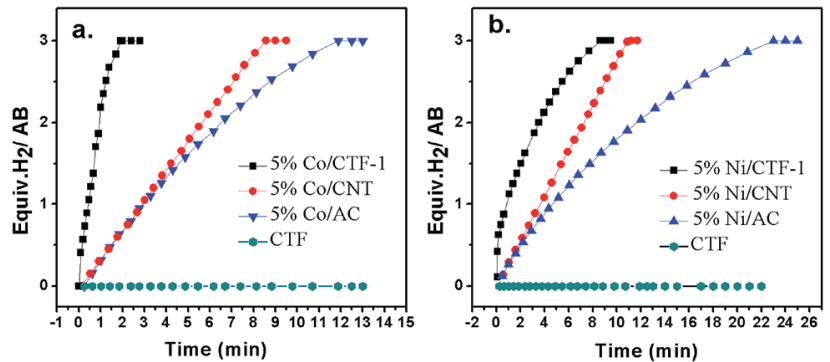

Fig. 3 Plots of volume of $\mathrm{H}_{2}$ generated vs. time for $\mathrm{AB}$ hydrolysis catalyzed by (a) $5 \% \mathrm{Co} / \mathrm{CTF}-1,5 \% \mathrm{Co} / \mathrm{CNT}, 5 \% \mathrm{Co} / \mathrm{AC}, \mathrm{CTF}$ (b) $5 \% \mathrm{Ni} /$ CTF-1, 5\% Ni/CNT, 5\% Ni/AC, CTF. ([AB] $=322 \mathrm{mM}, 5 \mathrm{~mL}, n_{\text {metal }} / n_{\mathrm{AB}}=$ $0.05)$.
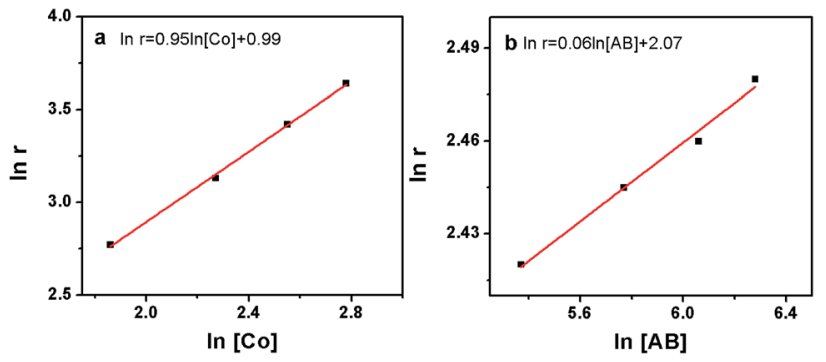

Fig. 4 (a) The plot of hydrogen generation rate versus the concentration of Co both in natural logarithmic scale, $\ln ($ rate $)=0.95 \ln [\mathrm{Co}]+$ 0.99; (b) the plot of hydrogen generation rate versus the concentration of $A B$ both in natural logarithmic scale, $\ln ($ rate $)=0.06 \ln [A B]+2.07$.

with respect to the concentration of $A B$ (Fig. $4 \mathrm{~b}$ ), which implies that $\mathrm{AB}$ is easy to activate. Therefore, the activation of $\mathrm{AB}$ should not be involved in the RDS, which was in accordance with our KIE results. The kinetic order of $\mathrm{H}_{2} \mathrm{O}$ was also measured in a dimethoxymethane (glyme) solution. As shown in Fig. $\mathrm{S} 4, \dagger$ the slope of 1.27 of $\ln \left(\right.$ rate) versus $\ln \left[\mathrm{H}_{2} \mathrm{O}\right]$ indicates that the hydrolysis of $\mathrm{AB}$ was first-order with respect to $\mathrm{H}_{2} \mathrm{O}$ concentration.

A KIE value of 2.8 was determined for deuteration at $\mathrm{H}_{2} \mathrm{O}\left(\mathrm{D}_{2} \mathrm{O}\right)$ for the Co/CTF-1 catalyst, while no KIE was found for deuteration at boron $\left(\mathrm{NH}_{3} \mathrm{BD}_{3}\right)$ (Fig. S5 $\dagger$ ), suggesting a similar reaction pathway as the $\mathrm{Co} / \mathrm{CNT}$ and $\mathrm{Co} / \mathrm{AC}$ catalyzed reaction where the activation of the $\mathrm{O}-\mathrm{H}$ bond was still the RDS for the $\mathrm{AB}$ hydrolysis reaction.

The reusability of the as-synthesized catalyst under the current room-temperature conditions is critical for practical applications. As shown in Fig. 5, the activity of the Co/CTF-1 catalyst was essentially retained after 5 cycles although a slight drop in reaction rate was observed, which may be attributed to (1) the diluted reactant in water; (2) the increase of solution viscidity with the increasing number of test cycles; ${ }^{78}$ (3) the catalyst surface becoming covered with boron species. Furthermore, TEM images (Fig. S6†) showed that the particle size of Co gradually increased during the tests, which may be caused by aggregation or the deposited borate layer on Co NPs. ${ }^{18,30}$ Nevertheless, the catalysts can be easily separated from the reaction

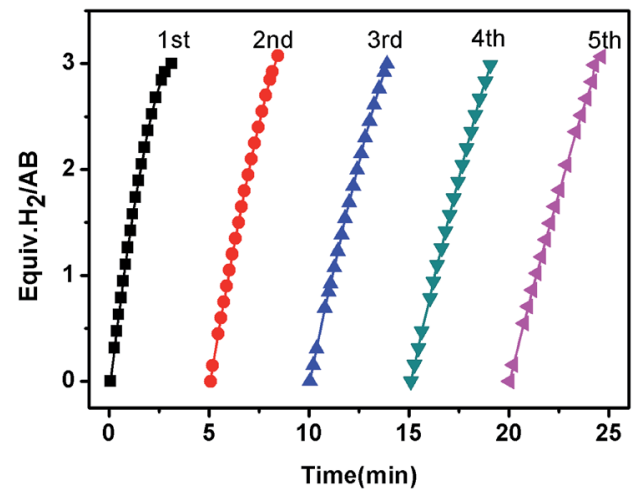

Fig. 5 The plots of volume of $\mathrm{H}_{2}$ vs. time for hydrolysis of $\mathrm{AB}$ catalyzed by the $5 \% \mathrm{Co} / \mathrm{CTF}-1$ catalyst during a five-cycle reusability test. 
system and recycled following $\mathrm{Xu}$ 's $\operatorname{method}^{79}$ due to the magnetism of cobalt (Fig. S7†).

\section{Discussion}

As mentioned above, the better dispersion of Co on CTF-1 than that of Co on AC and CNT, which can probably be ascribed to the anchoring effect of $\mathrm{N}$ on the pore rim of CTF- $1,{ }^{75-77}$ could be one of the reasons for the better activity of $\mathrm{Co} / \mathrm{CTF}$. To exclude the particle size effect, Co/CNT catalysts with lower loadings, i.e., $1 \%$ and $3 \%$, were synthesized, aiming to obtain similar particle sizes to those of Co on CTF-1. As can be seen from Fig. S8, $\uparrow$ the $1 \% \mathrm{Co} / \mathrm{CNT}$ had an average particle size of $3.7 \mathrm{~nm}$ which was comparable to that of $5 \% \mathrm{Co} / \mathrm{CTF}-1$. However, the catalytic activity (TOF of $18.8 \mathrm{~mol}_{\mathrm{H}_{2}} \mathrm{~mol}_{\mathrm{Co}}{ }^{-1} \mathrm{~min}^{-1}$ ) (Fig. S9†) was much lower than that of $5 \% \mathrm{Co} / \mathrm{CTF}-1\left(33.5 \mathrm{~mol}_{\mathrm{H}_{2}} \operatorname{mol}_{\mathrm{Co}}{ }^{-1}\right.$ $\min ^{-1}$ ). Therefore, the better activity of $\mathrm{Co} / \mathrm{CTF}-1$ should be mainly related to the electronic property of Co. As CTF-1 is an electron donating support, we suspected that Co on CTF-1 would be electron-rich, which would be in favour of $\mathrm{H}_{2} \mathrm{O}$ activation. To confirm the electron transfer between Co NPs and the supports (CTF-1, AC and CNT), X-ray photoelectron spectroscopy (XPS) measurements with and without Ar sputtering were performed (Fig. S10 $\dagger$ and 6). Before Ar sputtering, all the Co signals (supported by CTF-1, AC and CNT) can be resolved into two spin-orbit pairs with $2 \mathrm{p}_{3 / 2}$ and $2 \mathrm{p}_{1 / 2}$ binding energies, respectively (Fig. S10 $†$ ). The binding energies at 780.7 and $796.5 \mathrm{eV}$ can be attributed to $\mathrm{Co}^{2+}$, and at 787.2 and $803.0 \mathrm{eV}$ to $\mathrm{Co}^{3+}$ species, respectively (Fig. $\left.\mathrm{S} 10 \dagger\right) .{ }^{\mathbf{8 0 , 8 1}}$ The formation of $\mathrm{Co}^{2+}$ and $\mathrm{Co}^{3+}$ species was probably caused by air oxidation during sample loading into the XPS chamber. After $\mathrm{Ar}^{+}$sputtering, a new spin-orbit pair with $2 \mathrm{p}_{3 / 2}$ and $2 \mathrm{p}_{1 / 2}$ binding energies assignable to metallic Co can be detected (Fig. 6), ${ }^{79}$ which was in agreement with the high resolution TEM result. As we expected, the binding energy for Co $2 \mathrm{p}$ in Co/CTF-1 had a downshift of

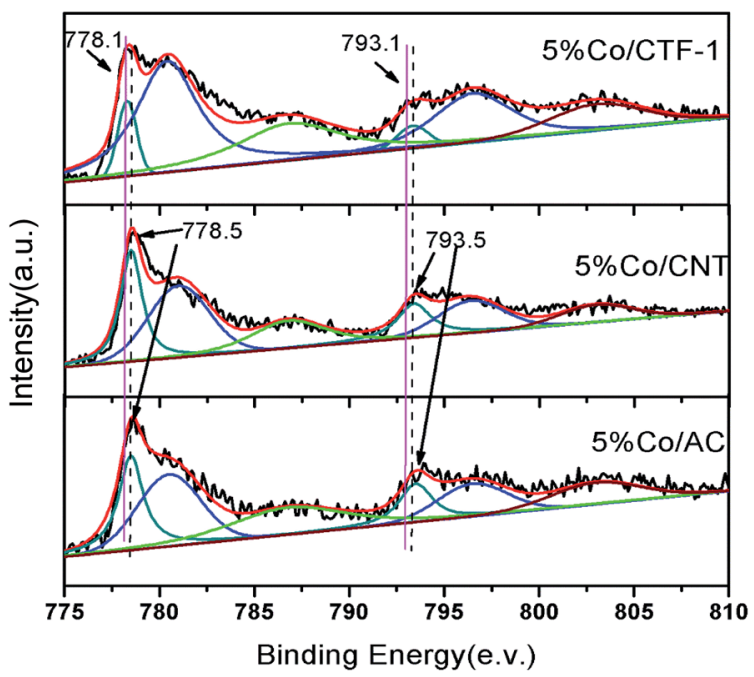

Fig. 6 XPS spectra of Co $2 p_{3 / 2}$ and $2 p_{1 / 2}$ in $5 \%$ Co/CTF-1, $5 \%$ Co/CNT and $5 \% \mathrm{Co} / \mathrm{AC}$ samples. All samples were pre-treated with $\mathrm{Ar}^{+}$ sputtering. $\sim 0.4 \mathrm{eV}$ compared to that of $\mathrm{Co} / \mathrm{AC}$ and $\mathrm{Co} / \mathrm{CNT}$ (Fig. 6), indicating an electron-rich state of Co on CTF-1, which also reflected electron transfer from CTF-1 to Co. As we mentioned in the catalyst design section, electron rich metals benefit several catalytic reactions, including the activation of $\mathrm{N}-\mathrm{H}, \mathrm{C}-\mathrm{H}$, and $\mathrm{O}-\mathrm{H}$ bonds. ${ }^{57,59,61}$ In accordance with the previous investigations mentioned above, we propose that such an electron-rich state would benefit the electron transfer from Co to the antibonding orbital of $\mathrm{H}_{2} \mathrm{O}$ molecules, resulting in effective activation of $\mathrm{H}_{2} \mathrm{O}$. Therefore, the negatively charged Co on CTF may favour the activation of $\mathrm{H}_{2} \mathrm{O}$ molecules.

As $\mathrm{H}_{2} \mathrm{O}$ activation correlates with the electronic structure of transition metals, ${ }^{\mathbf{5 1 , 8 2}}$ the apparent activation energy $\left(E_{\mathrm{a}}\right)$ of $\mathrm{Co} / \mathrm{CFT}-1$ would be reduced compared to $\mathrm{Co} / \mathrm{CNT}$ or $\mathrm{Co} / \mathrm{AC}$. To confirm this, the time dependence of $\mathrm{H}_{2}$ generation at different temperatures was recorded (illustrated in Fig. 7) to determine the $E_{\mathrm{a}}$ through the Arrhenius equation (eqn (2)).

$$
\ln k=\ln A-\frac{E_{\mathrm{a}}}{R T}
$$

Fig. 7b shows the Arrhenius plot of $\ln k v s .1 / T$, from which $E_{\mathrm{a}}$ can be calculated to be $42.7 \mathrm{~kJ} \mathrm{~mol}^{-1}$ for the $\mathrm{Co} / \mathrm{CTF}-1$ catalyst, and 46.9 and $47.2 \mathrm{~kJ} \mathrm{~mol}^{-1}$ for $\mathrm{Co} / \mathrm{AC}$ and $\mathrm{Co} / \mathrm{CNT}$, respectively. The $c a .10 \%$ decrease in $E_{\mathrm{a}}$ for the Co/CTF-1 catalyst suggested a favourable transition state with a lower energy barrier, which may be ascribed to the fact that the electron-rich Co was beneficial for the activation of $\mathrm{H}_{2} \mathrm{O}$ molecules. In contrast to the acid catalyzed hydrolysis of $\mathrm{AB}$, where the $\mathrm{H}^{+}$either attacks $\mathrm{NH}_{3}$ or $\mathrm{BH}_{3},{ }^{\mathbf{8 3 , 8 4}}$ the activation of $\mathrm{H}_{2} \mathrm{O}$ and the following steps in our case should occur on the surface of $\mathrm{Co}^{85}$ It is likely that homolytic activation of $\mathrm{H}_{2} \mathrm{O}$ may take place giving rise to $-\mathrm{H}$ and $-\mathrm{OH}$, which further react with activated $\mathrm{AB}$ to form $\mathrm{B}-\mathrm{OH}$ and $\mathrm{H}_{2}{ }^{41}$ A schematic drawing showing catalytic $\mathrm{AB}$ hydrolysis on Co/CTF-1 is presented (see Scheme 1). Owing to the abundance of $\mathrm{N}$ in the CTF support, its lone pair electrons may donate partially to Co particles, leading to an electron rich state of Co (as also evidenced by the XPS characterization), which is beneficial to the activation of $\mathrm{H}_{2} \mathrm{O}$, the rate determining step in the hydrolytic reaction. As a consequence, significantly improved catalytic activity, $42.3 \mathrm{~mol}_{\mathrm{H}_{2}} \mathrm{~mol}_{\mathrm{Co}}{ }^{-1} \mathrm{~min}^{-1}$ for the $3 \% \mathrm{Co} / \mathrm{CTF}-1$ catalyst, can be achieved.
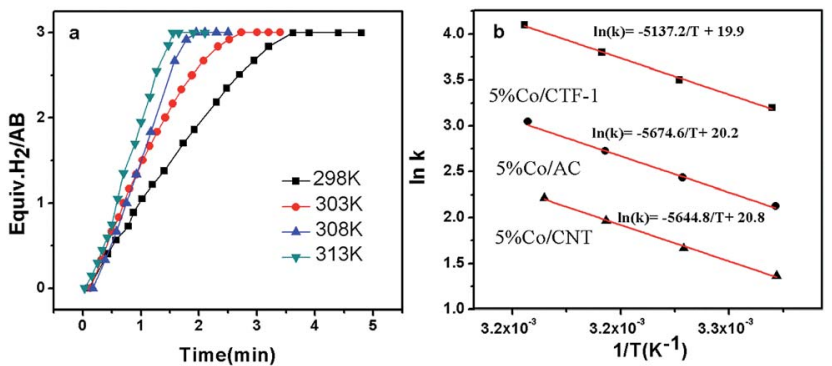

Fig. 7 (a) Plots of volume of $\mathrm{H}_{2}$ vs. time for the $5 \% \mathrm{Co} / \mathrm{CTF}-1$ catalyzed hydrolysis of $A B$ at temperatures in the range of $298-313 \mathrm{~K}$, catalyst/AB $=0.05$; (b) Arrhenius plots obtained from the kinetic data of $5 \% \mathrm{Co} /$ CTF-1, 5\% Co/CNT, and 5\% Co/AC. 


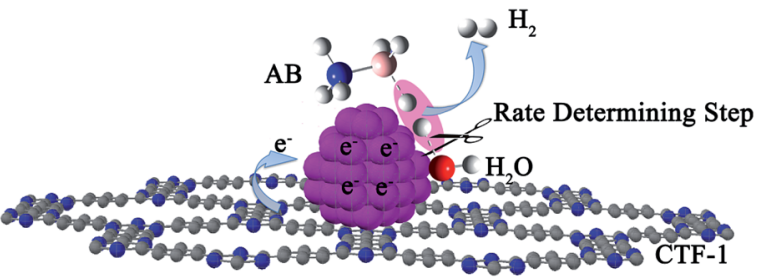

Scheme 1 Proposed mechanism for the catalytic hydrolysis of AB by Co/CTF-1.

\section{Conclusions}

The KIE measurements show that the RDS for $\mathrm{AB}$ hydrolysis is the breaking of an $\mathrm{O}-\mathrm{H}$ bond in $\mathrm{H}_{2} \mathrm{O}$. Transition metals with an optimal electron structure that bonds $\mathrm{H}_{2} \mathrm{O}$ and $-\mathrm{OH}$ in intermediate strengths may facilitate the hydrolysis of $\mathrm{AB}$. Rich in $\mathrm{N}$, the newly developed CTF-1 has an electron donating effect that markedly increases the electron density of the Co or Ni supported on it. As a consequence, significantly enhanced catalytic activity in $\mathrm{AB}$ hydrolysis has been achieved. Specifically, the 3\% Co/CTF-1 catalyst exhibited an activity (TOF of 42.3 mol $_{\mathrm{H}_{2}}$ $\mathrm{mol}_{\mathrm{Co}}{ }^{-1} \mathrm{~min}^{-1}$ ) that is higher than ever reported for its peer non-noble metal catalysts and even comparable to some noble metal catalysts. The results reported here may pave the way for the rational design of even more highly active catalysts for $\mathrm{AB}$ hydrolysis and other reactions.

\section{Experimental section}

\section{Materials}

Terephthalonitrile (liquid chromatogram, Merck), zinc chloride $\left(\mathrm{ZnCl}_{2}, 98 \%\right.$, Aldrich), ammonium carbonate $\left(\left(\mathrm{NH}_{4}\right)_{2} \mathrm{CO}_{3}\right.$, analysis, Acros), sodium borohydride $\left(\mathrm{NaBH}_{4}, 98 \%\right.$, Aldrich), cobalt nitrate $\left(\mathrm{Co}\left(\mathrm{NO}_{3}\right)_{2}\right.$, analysis, Kermel), nickel nitrate $\left(\mathrm{Ni}\left(\mathrm{NO}_{3}\right)_{2}\right.$, analysis, Kermel), activated charcoal (AC, 20-40 mesh, Aldrich), carbon nanotube (CNT, SMWNT-1020, Shenzhen nanotech port. Co.), ethanol (analysis, Damao) and deuterium oxide (99\%, Aldrich) were used without further purification. $\mathrm{AB}, \mathrm{NH}_{3} \mathrm{BD}_{3}$ and CTF-1 were synthesized according previous reports. ${ }^{70,86,87}$

\section{Preparation of catalysts}

$5 \% \mathrm{Co} / \mathrm{AC}$ and $5 \% \mathrm{Co} / \mathrm{CNT}$ catalysts were prepared by incipient wetness impregnation with ethanol solutions of $\mathrm{Co}\left(\mathrm{NO}_{3}\right)_{2}$ and $\mathrm{Ni}\left(\mathrm{NO}_{3}\right)_{2}$, respectively. Briefly, the $\mathrm{Co}^{2+}$ or $\mathrm{Ni}^{2+}$ solutions were dropped into supports uniformly. After ultra-sonication for $20 \mathrm{~min}$, the mixtures were dried at $50{ }^{\circ} \mathrm{C}$ for $6 \mathrm{~h}$ then $100{ }^{\circ} \mathrm{C}$ for $12 \mathrm{~h}$. Subsequently, they were calcined under an argon atmosphere at $350{ }^{\circ} \mathrm{C}$ for $4 \mathrm{~h}$. Then, the samples were reduced under a $\mathrm{H}_{2}$ atmosphere with a flow rate of $40 \mathrm{~mL} \mathrm{~min}^{-1}$ at $400{ }^{\circ} \mathrm{C}$ for $4 \mathrm{~h}$. Finally, the catalysts were transferred under the protection of Ar to the MBRAUN glove box to avoid oxidation or contamination. The same procedure was employed to prepare $5 \% \mathrm{Co} /$ CTF-1, 3\% Co/CTF-1, 3\% Co/CNT, 1\% Co/CNT, 5\% Ni/CNT, 5\% $\mathrm{Ni} / \mathrm{AC}$ and $5 \% \mathrm{Ni} / \mathrm{CTF}-1$ catalysts.

\section{Catalytic hydrolysis of $\mathrm{AB}$}

The as-prepared catalyst was dispersed into $2 \mathrm{~mL}$ of deionized (DI) water in a three-necked round-bottom flask. After that, $0.05 \mathrm{~g} \mathrm{AB}$ dissolved in $3 \mathrm{~mL}$ DI water was injected into the catalyst suspension with a syringe under vigorous stirring. The reaction was carried out at room temperature. The evolution of gas was monitored using a gas buret. In order to investigate the reactivity kinetics, the effect of reaction temperature was studied at different temperatures $(298 \mathrm{~K}, 303 \mathrm{~K}, 308 \mathrm{~K}, 313 \mathrm{~K})$ for the hydrolysis of $322 \mathrm{mM} \mathrm{NH}_{3} \mathrm{BH}_{3}$ catalyzed by $16 \mathrm{mM} \mathrm{Co} / \mathrm{CTF}-1$. The kinetics order of $\mathrm{H}_{2} \mathrm{O}$ was measured in $5 \mathrm{~mL}$ dimethoxymethane with different concentrations of $\mathrm{H}_{2} \mathrm{O}(1161 \mathrm{mM}$, $950 \mathrm{mM}, 739 \mathrm{mM}, 528 \mathrm{mM}$ ) by using the $5 \% \mathrm{Co} / \mathrm{CNT}$ catalyst. TOFs were calculated on the basis of the moles of total metal, following the common methods in literature, where the metal dispersion was not calculated. In fact, the TOF of the catalyst will increase if metal dispersion is considered. All the hydrolysis experiments were monitored in the same way. After the hydrolysis reaction was exhaustively completed, another new batch of $\mathrm{NH}_{3} \mathrm{BH}_{3}$ dissolved in $2 \mathrm{~mL}$ of DI water was injected into the solution for testing the recycling stability of the catalyst. The same process was repeated 4 times. All of the catalyst transferring, loading and hydrolysis reactions were conducted under an argon atmosphere to avoid any oxidation and contamination.

\section{Characterization}

TEM (JEM-2100F operating at $200 \mathrm{kV}$ ) was used to observe the morphology of catalysts. XRD data were collected on a PANalytical X'pert diffractometer equipped with $\mathrm{Cu} \mathrm{K} \alpha$ radiation (40 kV, $40 \mathrm{~mA}$ ). NMR experiments were performed on a Bruker AVANCE $500 \mathrm{MHz}$ NMR spectrometer (11.7 T) at room temperature with the reference to $\mathrm{BF}_{3}$ ethyl ether solution at $0 \mathrm{ppm}$. The specific surface area was measured on an Autosorb-1 system (Quantachrome, USA) by a $\mathrm{N}_{2}$ adsorption isotherm through the BET method. The actual Co loadings of the prepared catalysts were determined using ICP spectrometry (ICP-OES, optima 7300DV, Perkin-Elmer, USA). The XPS measurements were performed using an Escalab $250 \mathrm{Xi}$ X-ray photoelectron spectrometer (Thermo Scientific) with nonmonochromatic $\mathrm{Al} \mathrm{K} \alpha$ radiation (photon energy, $1486.6 \mathrm{eV}$ ), where the sample loading was conducted in air, which may lead to surface oxidization. In order to remove the oxidation layers, the Ar sputtering experiments were performed at a background vacuum of $3.4 \times 10^{-6} \mathrm{~Pa}$, a sputtering acceleration voltage of $2 \mathrm{kV}$, and a sputtering current of $10 \mathrm{~mA}$. Adventitious carbon was used to calibrate the binding energy shifts of the samples $(\mathrm{C} 1 \mathrm{~s}=284.8 \mathrm{eV}){ }^{88}$

\section{Acknowledgements}

The authors would like to acknowledge financial support from the project of National Natural Science Funds for Distinguished Young Scholar (51225206), projects of National Natural Science Foundation of China (Grant No. 51301161, 21473181 and 51472237) and projects from the Collaborative Innovation Center of Chemistry for Energy Materials and the Youth Innovation Promotion Association (CAS). 


\section{References}

1 M. Valden, X. Lai and D. W. Goodman, Science, 1998, 281, 1647-1650.

2 B. Lim, M. Jiang, P. H. C. Camargo, E. C. Cho, J. Tao, X. Lu, Y. Zhu and Y. Xia, Science, 2009, 324, 1302-1305.

3 L. Gan, M. Heggen, S. Rudi and P. Strasser, Nano Lett., 2012, 12, 5423-5430.

4 M. Kitano, Y. Inoue, Y. Yamazaki, F. Hayashi, S. Kanbara, S. Matsuishi, T. Yokoyama, S.-W. Kim, M. Hara and H. Hosono, Nat. Chem., 2012, 4, 934-940.

5 N. Armaroli and V. Balzani, ChemSusChem, 2011, 4, 21-36.

6 J. Yang, A. Sudik, C. Wolverton and D. J. Siegel, Chem. Soc. Rev., 2010, 39, 656-675.

7 L. Schlapbach and A. Züttel, Nature, 2001, 414, 353-358.

8 F. H. Stephens, V. Pons and R. T. Baker, Dalton Trans., 2007, 2613-2626.

9 C. W. Hamilton, R. T. Baker, A. Staubitz and I. Manners, Chem. Soc. Rev., 2009, 38, 279-293.

10 Q. L. Zhu and Q. Xu, Energy Environ. Sci., 2015, 8, 478-512.

11 M. Bowden, T. Autrey, I. Brown and M. Ryan, Curr. Appl. Phys., 2008, 8, 498-500.

12 F. Baitalow, J. Baumann, G. Wolf, K. Jaenicke-Rossler and G. Leitner, Thermochim. Acta, 2002, 391, 159-168.

13 A. Gutowska, L. Li, Y. Shin, C. M. Wang, X. S. Li, J. C. Linehan, R. S. Smith, B. D. Kay, B. Schmid, W. Shaw, M. Gutowski and T. Autrey, Angew. Chem., Int. Ed., 2005, 44, 3578-3582.

14 Q. Xu and M. Chandra, J. Power Sources, 2006, 163, 364-370. 15 M. Chandra and Q. Xu, J. Power Sources, 2007, 168, 135-142. 16 H.-L. Jiang, S. K. Singh, J.-M. Yan, X.-B. Zhang and Q. Xu, ChemSusChem, 2010, 3, 541-549.

17 J.-M. Yan, X.-B. Zhang, S. Han, H. Shioyama and Q. Xu, Angew. Chem., Int. Ed., 2008, 47, 2287-2289.

18 O. Metin, V. Mazumder, S. Ozkar and S. S. Sun, J. Am. Chem. Soc., 2010, 132, 1468.

19 Z. H. Lu, H. L. Jiang, M. Yadav, K. Aranishi and Q. Xu, J. Mater. Chem., 2012, 22, 5065-5071.

20 F. Cheng, H. Ma, Y. Li and J. Chen, Inorg. Chem., 2007, 46, 788-794.

21 D. Sun, V. Mazumder, O. Metin and S. Sun, ACS Nano, 2011, 5, 6458-6464.

22 J.-M. Yan, X.-B. Zhang, T. Akita, M. Haruta and Q. Xu, J. Am. Chem. Soc., 2010, 132, 5326-5327.

23 N. Cao, J. Su, X. Hong, W. Luo and G. Cheng, Chem.-Asian J., 2014, 9, 562-571.

24 G. Chen, S. Desinan, R. Nechache, R. Rosei, F. Rosei and D. Ma, Chem. Commun., 2011, 47, 6308-6310.

25 F. Qiu, L. Li, G. Liu, C. Xu, C. An, Y. Xu, Y. Wang, Y. Huang, C. Chen, Y. Wang, L. Jiao and H. Yuan, Chem.-Asian J., 2014, 9, 487-493.

26 A. Aijaz, A. Karkamkar, Y. J. Choi, N. Tsumori, E. Roennebro, T. Autrey, H. Shioyama and Q. Xu, J. Am. Chem. Soc., 2012, 134, 13926-13929.

27 Y. Li, L. Xie, Y. Li, J. Zheng and X. Li, Chem.-Eur. J., 2009, 15, 8951-8954.
28 J. Li, Q.-L. Zhu and Q. Xu, Chem. Commun., 2014, 50, 58995901.

29 Q.-L. Zhu, J. Li and Q. Xu, J. Am. Chem. Soc., 2013, 135, 10210-10213.

30 W. Chen, J. Ji, X. Feng, X. Duan, G. Qian, P. Li, X. Zhou, D. Chen and W. Yuan, J. Am. Chem. Soc., 2014, 136, 1673616739.

31 M. Mahyari and A. Shaabani, J. Mater. Chem. A, 2014, 2, 16652-16659.

32 L. Yang, W. Luo and G. Cheng, ACS Appl. Mater. Interfaces, 2013, 5, 8231-8240.

33 P. Xi, F. Chen, G. Xie, C. Ma, H. Liu, C. Shao, J. Wang, Z. Xu, $\mathrm{X}$. Xu and Z. Zeng, Nanoscale, 2012, 4, 5597-5601.

34 L.-T. Guo, Y.-Y. Cai, J.-M. Ge, Y.-N. Zhang, L.-H. Gong, X.-H. Li, K.-X. Wang, Q.-Z. Ren, J. Su and J.-S. Chen, ACS Catal., 2014, 5, 388-392.

35 Ö. Metin, S.. Şahin and S. Özkar, Int. J. Hydrogen Energy, 2009, 34, 6304-6313.

36 S. Karahan, M. Zahmakran and S. Ozkar, Chem. Commun., 2012, 48, 1180-1182.

37 W. Chen, J. Ji, X. Duan, G. Qian, P. Li, X. Zhou, D. Chen and W. Yuan, Chem. Commun., 2014, 50, 2142-2144.

38 S. B. Kalidindi, U. Sanyal and B. R. Jagirdar, Phys. Chem. Chem. Phys., 2008, 10, 5870-5874.

39 G. C. Fortman, A. M. Z. Slawin and S. P. Nolan, Organometallics, 2011, 30, 5487-5492.

40 J. Hu, Z. Chen, M. Li, X. Zhou and H. Lu, ACS Appl. Mater. Interfaces, 2014, 6, 13191-13200.

41 H. Ma and C. Na, ACS Catal., 2015, 5, 1726-1735.

42 C. Y. Peng, L. Kang, S. Cao, Y. Chen, Z. S. Lin and W. F. Fu, Angew. Chem., Int. Ed., 2015, 54, 15725-15729.

43 Q. Xu and M. Chandra, J. Alloys Compd., 2007, 446-447, 729732.

44 K. C. Westaway, J. Labelled Compd. Radiopharm., 2007, 50, 989-1005.

45 G. Guella, B. Patton and A. Miotello, J. Phys. Chem. C, 2007, 111, 18744-18750.

46 E. M. Simmons and J. F. Hartwig, Angew. Chem., Int. Ed., 2012, 51, 3066-3072.

47 G. Guella, C. Zanchetta, B. Patton and A. Miotello, J. Phys. Chem. B, 2006, 110, 17024-17033.

48 L. R. Peebles and P. Marshall, J. Chem. Phys., 2002, 117, 3132-3138.

49 P. R. Rablen, J. Am. Chem. Soc., 1997, 119, 8350-8360.

50 R. J. Keaton, J. M. Blacquiere and R. T. Baker, J. Am. Chem. Soc., 2007, 129, 1844-1845.

51 S. L. Suib, S. L. Brock, M. Marquez, J. Luo, H. Matsumoto and Y. Hayashi, J. Phys. Chem. B, 1998, 102, 9661-9666.

52 A. Kudo and Y. Miseki, Chem. Soc. Rev., 2009, 38, 253-278.

53 F. Abild-Pedersen, J. Greeley, F. Studt, J. Rossmeisl, T. Munter, P. G. Moses, E. Skulason, T. Bligaard and J. K. Nørskov, Phys. Rev. Lett., 2007, 99, 016105.

54 S. Wang, V. Petzold, V. Tripkovic, J. Kleis, J. G. Howalt, E. Skulason, E. Fernandez, B. Hvolbæk, G. Jones and A. Toftelund, Phys. Chem. Chem. Phys., 2011, 13, 2076020765. 
55 N. Roy, K. T. Leung and D. Pradhan, J. Phys. Chem. C, 2015, 119, 19117-19125.

56 J.-J. Zou, H. He, L. Cui and H.-Y. Du, Int. J. Hydrogen Energy, 2007, 32, 1762-1770.

57 W. Wei, Y. Dai, M. Guo, Y. Ma and B. Huang, J. Solid State Chem., 2012, 187, 64-69.

58 F.-C. Wang, C.-H. Liu, C.-W. Liu, J.-H. Chao and C.-H. Lin, J. Phys. Chem. C, 2009, 113, 13832-13840.

59 F. Chang, J. Guo, G. Wu, L. Liu, M. Zhang, T. He, P. Wang, P. Yu and P. Chen, RSC Adv., 2015, 5, 3605-3610.

60 Y. Marco, L. Roldán, S. Armenise and E. García-Bordejé, ChemCatChem, 2013, 5, 3829-3834.

61 L. Li, X. Mu, W. Liu, Z. Mi and C.-J. Li, J. Am. Chem. Soc., 2015, 137, 7576-7579.

62 X. Ning, H. Yu, F. Peng and H. Wang, J. Catal., 2015, 325, 136-144.

63 Z. Li, J. Liu, C. Xia and F. Li, ACS Catal., 2013, 3, 2440-2448. 64 P. Zhang, Y. Gong, H. Li, Z. Chen and Y. Wang, Nat. Commun., 2013, 4, 1593.

65 R. Czerw, M. Terrones, J.-C. Charlier, X. Blase, B. Foley, R. Kamalakaran, N. Grobert, H. Terrones, D. Tekleab and P. Ajayan, Nano Lett., 2001, 1, 457-460.

66 Y. Zhou, K. Neyerlin, T. S. Olson, S. Pylypenko, J. Bult, H. N. Dinh, T. Gennett, Z. Shao and R. O'Hayre, Energy Environ. Sci., 2010, 3, 1437-1446.

67 H. Wang, T. Maiyalagan and X. Wang, ACS Catal., 2012, 2, 781-794.

68 S. Armenise, L. Roldaán, Y. Marco, A. Monzón and E. GarcíaBordejeé, J. Phys. Chem. C, 2012, 116, 26385-26395.

69 O. Y. Podyacheva and Z. R. Ismagilov, Catal. Today, 2015, 249, 12-22.

70 P. Kuhn, M. Antonietti and A. Thomas, Angew. Chem., Int. Ed., 2008, 47, 3450-3453.

71 P. Kuhn, A. Forget, D. Su, A. Thomas and M. Antonietti, J. Am. Chem. Soc., 2008, 130, 13333-13337.
72 C. E. Chan-Thaw, A. Villa, P. Katekomol, D. Su, A. Thomas and L. Prati, Nano Lett., 2010, 10, 537-541.

73 R. Palkovits, M. Antonietti, P. Kuhn, A. Thomas and F. Schüth, Angew. Chem., Int. Ed., 2009, 48, 6909-6912.

74 C. E. Chan-Thaw, A. Villa, L. Prati and A. Thomas, Chem.Eur. J., 2011, 17, 1052-1057.

75 T. He, L. Liu, G. Wu and P. Chen, J. Mater. Chem. A, 2015, 3, 16235-16241.

76 Y. Wang, J. Yao, H. Li, D. Su and M. Antonietti, J. Am. Chem. Soc., 2011, 133, 2362-2365.

77 P. Chen, L. M. Chew and W. Xia, J. Catal., 2013, 307, 84-93.

78 U. Sanyal, U. B. Demirci, B. R. Jagirdar and P. Miele, ChemSusChem, 2011, 4, 1731-1739.

79 K. Aranishi, Q.-L. Zhu and Q. Xu, ChemCatChem, 2014, 6, 1375-1379.

80 M. C. Biesinger, B. P. Payne, A. P. Grosvenor, L. W. M. Lau, A. R. Gerson and R. S. C. Smart, Appl. Surf. Sci., 2011, 257, 2717-2730.

81 B. J. Tan, K. J. Klabunde and P. M. A. Sherwood, J. Am. Chem. Soc., 1991, 113, 855-861.

82 B. Xing and G.-C. Wang, Phys. Chem. Chem. Phys., 2014, 16, 2621-2629.

83 H. C. Kelly and V. B. Marriott, Inorg. Chem., 1979, 18, 28752878.

84 A. D'Ulivo, M. Onor and E. Pitzalis, Anal. Chem., 2004, 76, 6342-6352.

85 J. L. C. Fajín, M. N. D. S. Cordeiro, F. Illas and J. R. B. Gomes, J. Catal., 2010, 276, 92-100.

86 P. V. Ramachandran and P. D. Gagare, Inorg. Chem., 2007, 46, 7810-7817.

87 R. Cantelli, A. Paolone, O. Palumbo, F. Leardini, T. Autrey, A. Karkamkar and A. T. Luedtke, J. AlloysCompd., 2013, 580, S63-S66.

88 C. E. Chan-Thaw, A. Villa, G. M. Veith, K. Kailasam, L. A. Adamczyk, R. R. Unocic, L. Prati and A. Thomas, Chem.-Asian J., 2012, 7, 387. 